\title{
Blended Learning: Exploring new models for effective teaching and learning.
}

\author{
Dr. Radhika Devi V' ${ }^{1}$, N.Laxminadh ${ }^{2}$, \\ Y. Lavanya ${ }^{3}$ \\ Department of Science and Humanities, MLR Institute of \\ Technology, An Autonomous Institution, Affiliated to \\ JNTUH, Hyderabad, T.S., India. \\ ${ }^{1}$ Email: hodhumanities@mlrinstitutions.ac.in \\ 2Email:In.mphil@gmail.com \\ 33Email: lavivenu@gmail.com
}

\begin{abstract}
Outcome based education is emerging as a paradigm for revising and reorienting teaching / learning approaches. Innovation in content, delivery mechanism and assessment are the major challenges faced by higher educational institutions. Any method devised should enable the development of creative and critical thinking among the students. Chances for long term success can be strengthened by considering various methods. In the context of challenges, the potential of blended learning is discussed. The study aims to examine the impact of the paradigm shift in teaching methodologies empowering the faculty with pedagogical methods and analyses the impact of their implementation. In particular the active learning strategies that were implemented by $80 \%$ of the faculty has shown an impact on the improvement of student interest in the subject by $50 \%$.

Blending by use of multiple types of instructional methodologies by incorporating technology has transformed students from learners to leaders.
\end{abstract}

Keywords: Pedagogical methods, Problem solving, paradigm shift, innovation, creativity.

\author{
Corresponding Author \\ ${ }^{1}$ Department of Science and Humanities, \\ ${ }^{1}$ hodhumanities@mlrinstitutions.ac.in
}

\section{Introduction:}

Outcome based education focuses on enhancing the $21^{\text {st }}$ century skills - problem solving, innovation and creativity. Paradigm shift in the teaching methods that encourage open ended problem solving, critical thinking, and creativity, is experimented. Further, an attempt is made to understand the teachers' readiness to enhance his/her professional skills and responsive practices.

Blended learning provides teachers and students with an innovative learning environment that can stimulate and enhance the TL process. In the present paper, we discuss the results obtained from a blended learning method used at MLRIT. A total of 64 groups took part, with 960 students registered for the 2018-2019 academic year. The observations are that there are positive effects of improving the exam marks. Availability of technology encouraged faculty to use blended learning in their classrooms but the usage remains at a low level with faculty not understanding the methodology to implement. The main aim of adopting new methods in teaching methodologies is to help the development of faculty leadership in introducing innovation and creativity in science and engineering education.

To ensure the success of blended learning faculty must be empowered in planning the strategies. There is a misconception that blended learning approach is simply integrating technology in teaching. It is the ability of the faculty to gain advantage of technology in streamlining the process of effective learning.

Blended learning leverages technology in providing the learners control over the pace, place and path of their learning.

To ensure effective outcomes from the methods used institutions have to consider training their faculty in planning the strategies as per course appropriately. Badrul Khan's blended e-learning framework, referred as Khan's Octagonal Framework (see Figure 1) helps one to choose 
an appropriate blend of available resources. (http://BooksToRead.com/framework).

The framework helps to think, plan, execute, manage, and assess the blended learning programs.

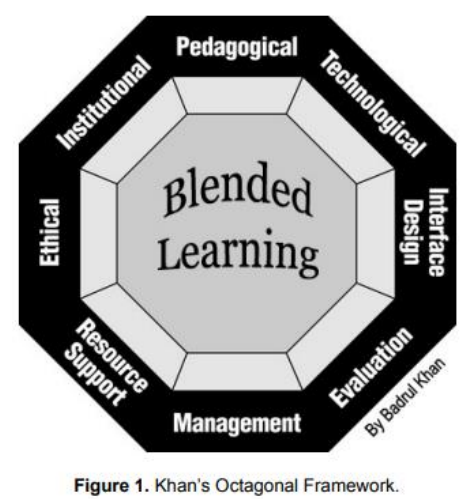

Fig:1 Blended Learning - image from google images

For the first year students, the following changes were made in teaching, and the impact of these changes are studied.

- ATLAS - Activities of Teaching \& Learning Active Strategies. Faculty have to teach at least one topic in every unit using active learning strategies in every subject and study their impact.

- COTs - Concept Oriented Tutorials were designed at analytical level (Bloom's level-4)

- Micro projects - Practising experiential learning.

- COSHISS - Consortium Of Students Helping Improve Speaking Skills

\section{Teaching Methods:}

Pedagogical strategies to use Bloom's Taxonomy in Teaching

Learning objective, combination of content that needs to be delivered and the student's capacity is taken into consideration. In this all the learning goals are listed and the appropriate method of delivery is chosen.

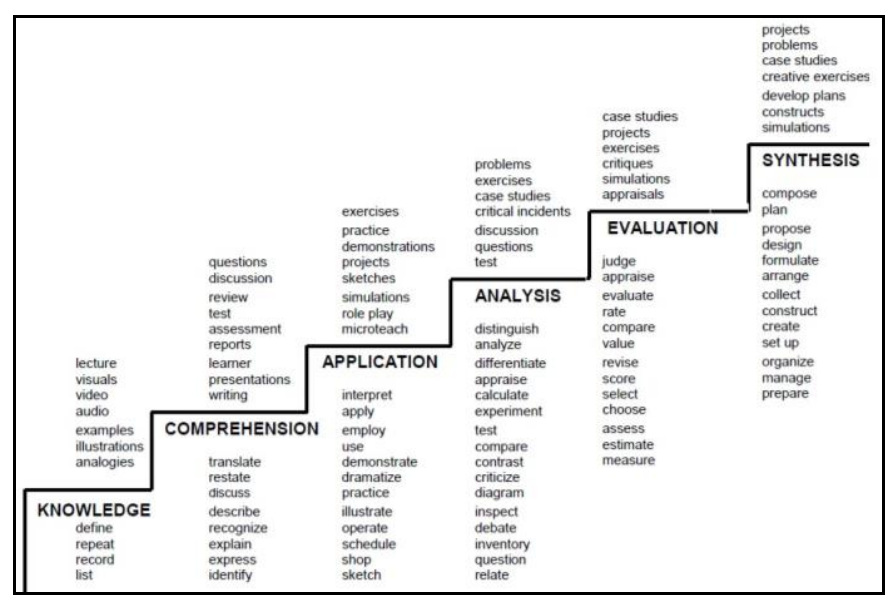

Fig:2 Bloom's taxonomy - image from google images

Bloom's level-1 - It's misunderstandings:

Memorization is misconstrued to reduce the students learning. It found that more diverse a student's background knowledge and schema are, students can smoothly undergo transition across the different Bloom's levels.

The cognitive load on a student can be reduced as they process information, allowing for fast recall and analyze rather than scattering the thinking process. It has to be realized that there is no high order thinking without lower order thinking (knowledge) and that retrieval of "mere facts" are actually very important. Matthew Levey of the International Charter School of New York has proposed the following analogy which clearly links different levels of Bloom.

(i) ATLAS - Activities of Teaching \& Learning Active Strategies:

Active learning instructional strategies share a common element of - "involving students in doing things and thinking about the things they are doing" (Bonwell \& Eison 1991) [2].

At MLRIT, two faculty members from each branch of engineering underwent the IIEECP (IUCEE International Engineers Education Certification Program). The certified faculty members, in turn, trained the other faculty members, the strategies of active learning.

The faculty were asked to mention the obstacles which might stop them from using active learning strategies. Following are the most common concerns cited:

- Syllabus completion in the given time might be effected.

- It's difficult to implement active learning strategies in large classes (Size of 60 students).

- Many of the faculty think of themselves as good lecturers, thereby they think that active learning strategies are not necessary.

- Using active learning strategies involves risk of students failing in exams.

The faculty members were asked to teach at least one topic in every unit using active learning strategies in every subject and study the impact.

The challenges faced by faculty in implementing and the experience gained were recorded. This was compiled as a book (ATLAS) for the junior faculty to refer before implementing the activities.

Following are few examples from a compiled book for implementing the activities.

i. Flipped class room followed by Think Pair Share (TPS) 
Flipped class room is one of the methods to ensure that the class time is spent on assimilation rather than information transfer. The faculty has to find video or a link of the topic to be watched / read by the student at home. Every flipped class must be followed by any of the activity to ensure students have watched / read the material.

While using Flipped class room concept, one has to understand that:

F - Flexible environment - we have to provide students with different ways to learn content and demonstrate mastery.

L - Learning Culture - we must give students opportunities to engage in meaningful activities without the teacher being central.

I - Intentional Content - We need to create and/or curate relevant content (typically videos) for our students.

P - Professional Educator - To become ourselves professional we have to collaborate and reflect with other educators and take responsibility for transforming our practices

\section{Flipping the class:}

Resource

a) Main video resource

https://www.youtube.com/watch?v=331ZkusUW OE\&list=PLDFF5A99731EFC6C\&index $=6$

\begin{tabular}{|l|l|}
\hline Segment & $\begin{array}{l}\text { Time } \\
\text { Duration }\end{array}$ \\
\hline Segment 1- Basic identities Part I & $13: 25 \mathrm{mins}$ \\
\hline Segment 2- Basic identities Part II & $06: 19 \mathrm{mins}$ \\
\hline Segment 3- Deriving Identities & $06: 09 \mathrm{mins}$ \\
\hline $\begin{array}{l}\text { Segment 4- Simplifying Circuits } \\
\text { using Identities }\end{array}$ & $05: 87 \mathrm{mins}$ \\
\hline
\end{tabular}

b) Slides shown in the video and reference text book chapter are provided as additional reference resources

\section{Think Pair Share}

Think ( $\sim 4$ minutes)

Instruction: Assuming that the Temperature and humidity of a station are Boolean variables Tn and $\mathrm{Hn}$ (where $\mathrm{n}$ is the station number). Think individually and identify the scenario(Boolean expression) in which a high output will occur from the area.

Pair ( 6 minutes)

Instruction: Now pair up and compare your answers. Conclude on one final answer. Instructor monitors the teams while the students start discussing.
Instruction: Once a final answer is arrived at assume that the two variables A\&B are used to select sensor output based on time, develop a Boolean expression to combine time selection and output selection.

\section{Pair ( $\sim 5$ minutes)}

Instruction: Now each group has to share the answers to the entire class. A feedback is given on the correct answer.

After the activity is completed the faculty writes his / her experiences.

For the above activity the following were the observations by the faculty:

a. One has to ensure that there is a clear 'outcome' for each phase. This drives the action in that phase.

b. All the three phases must be logically connected. The output of one phase should be the starting point for the next phase.

c. Do not conduct the activity in a hurry burry. Plan to have allotted sufficient time for each phase of the activity.

Important points to be noted:

$\checkmark$ If too little time is allotted students get frustrated.

$\checkmark$ If too much time is allotted students get bored.

$\checkmark$ Faculty has to move to the next phase if $75 \%$ of the class has completed the activity.

Group writing activity:

The activity be well implemented if the class size is 30 students.

Therefore in a typical class of 60 students, the students can be divided into 2 classes with 30 students in each class.

Students will be given a web link to go through and come to the class.

On the next day a group of 5 students will be made as team.

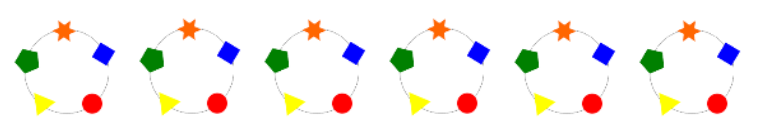

Fig 3:Arrangement of students for group writing activity. 
Each student in a team will be given a different badge. The above fig depicts the arrangement of students in 6 teams.

When the teams are ready the faculty announces the start point with one of the student.

After 5 mins the first member has to pass on the sheet to the next member who will be selected by the faculty. The next student has to continue from where the first student left and the process will continue.

(Eg; First - students with Star badge, next students with circle badge, next students with square batch, next students with pentagon badge, next students with triangle badge).

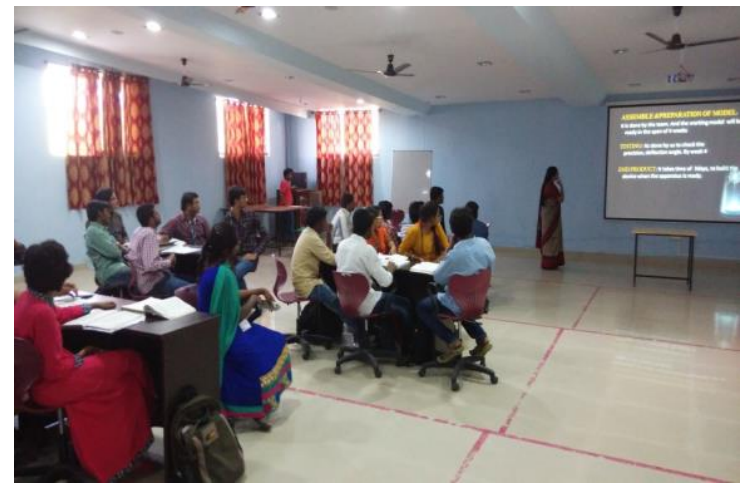

Fig 4: Group writing Activity in progress

All the students will actively participate and complete the answer.

Important points to be noted:

$\checkmark$ Faculty must provide a link for the topic. Should not say students have to prepare on their own the topic. Specific $\operatorname{link}(\mathrm{s})$ must be provided.

$\checkmark$ Selection of the team members should be done randomly to ensure every student comes well prepared.

$\checkmark$ Marks obtained by the team should be equally distributed among all students so that students take the responsibility of ensuring their friend perform well.

All the major obstacles were overcome in using ALS in the class rooms. Gradual adoption appropriate teaching strategies that increase student activity level within the context of their discipline has also shown its impact on the students attitudes.

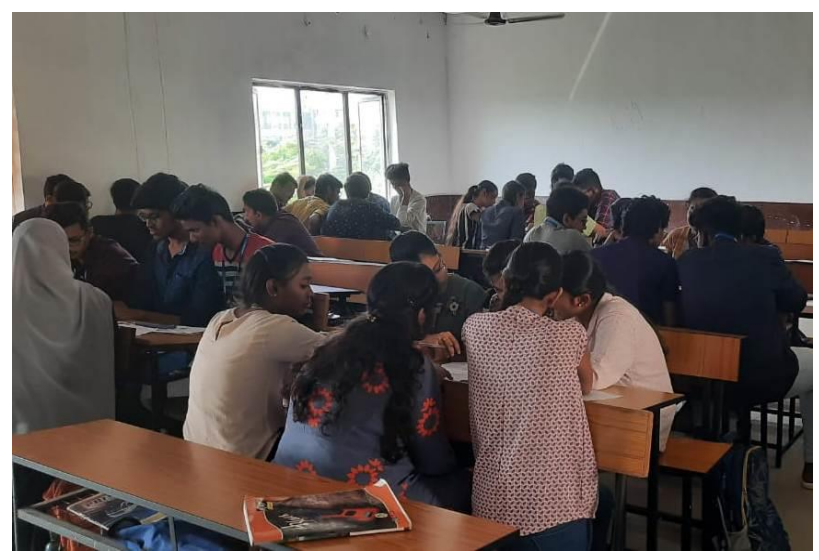

Fig 5: JIGSAW activity in progress

By carefully selecting only those active learning strategies that are at a personally comfortable risk level risk levels are minimized.

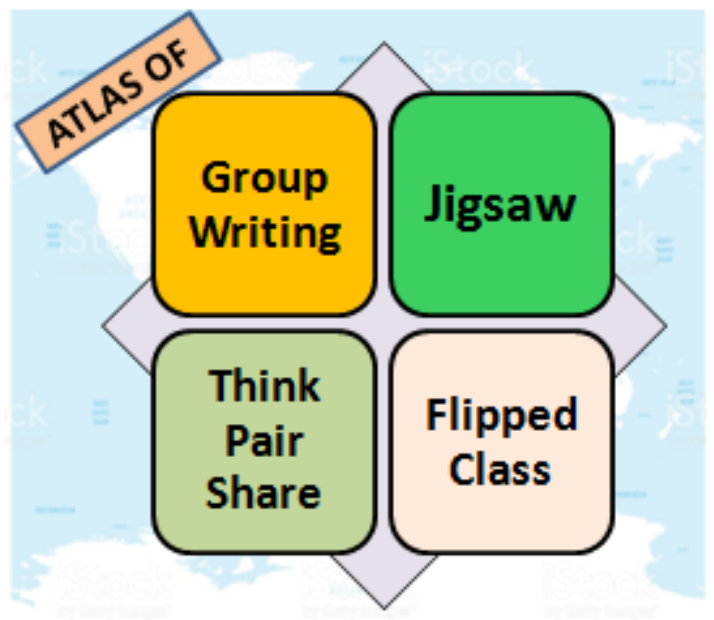

Fig 6: Cover Page of ATLAS - a quick reference guide

The impact of the active learning strategies was particularly measured and compared for 480 students. In six sections consisting of 60 students each, the activities were implemented and in other two sections traditional teaching method of chalk and talk only were used.

Pre/Post-Test Survey was conducted to assess student learning from the start of the course until the end. A pretest survey was conducted across all the 480 students at the beginning of the semester to capture the extent of student knowledge and understanding about key course concepts they study in that semester. A follow-up post test at the end of the semester was conducted and the results were compared.

For each student who participated in all the activities the total change in learning after the implementation of active learning strategies was calculated. Total points secured for every activity was collected and converted them to a percentage (up to 100). Making use of the converted values calculation of a normalized change (c) value for 
every student was performed. The normalized change value is the ratio of the observed change to the total possible change (Marx and Cummings 2007)[3]. Each individual c value was calculated as follows:

$$
\begin{aligned}
& \mathrm{c}=(\text { post-pre }) /(100-\text { pre }) ; \text { if post }>\text { pre } \\
& \mathrm{c}=(\text { post-pre }) / \text { pre; if post }<\text { pre } \\
& \mathrm{c}=0 ; \text { if post }=\text { pre } \\
& \text { drop; if pre }=\text { post }=0 \text { or } 100
\end{aligned}
$$

The value of $\mathrm{c}$ ranges between -1 and 1 . Gain is indicated by a positive $c$ value and loss by a negative value. No change is indicated by a zero value.

We obtained the overall average normalized change $\left(c_{\text {ave }}\right)$ for students with the individual $\mathrm{c}$ values.

Improvement in the student learning was noted during the single semester itself. While activities were administered to 360 students during the study period, a total of 341 students have completed all activities and the data was analysed for these. Total 246 students (72\%) improved (positive c value).

(ii) COTs - Concept Oriented Tutorials to improve Higher Order Thinking Skills (Bloom's level- 4\&5)

It's been identified that deficiencies exist in enhancing problem solving skills. The traditional model lacks in providing sufficient motivation for engineering undergraduates (Chu and Lai, 2002; Felder, 2006)[4\&5]. It is also argued that engineering educators tend to focus on teaching content rather than method (Wankat and Oreovicz, 1992).[6]

COTs activity was aimed at developing the critical and analytical skills where students are expected not only to understand what they read but also pick it apart, analyze, evaluate and assess.

We piloted the COTs in diverse classroom settings.

Following is a sample of the questions asked in the tutorials

1. A particle in a 1-D box has a minimum allowed energy of $2.5 \mathrm{eV}$.

(a) What is the next higher energy it can have? And the next higher after that? Does it have a maximum allowed energy?

(b) If the particle is an electron, how wide is the box?

(c) The fact that particles in a 1-D box have a minimum energy is not completely unrelated to the uncertainty principle. Find the minimum momentum of a particle, with mass $m$, trapped in a 1-D box of size L. How does this compare with the momentum uncertainty required by the uncertainty principle, if we assume $\Delta x=L$ ?
The analysis was done in engineering physics subject where the COTs was implemented in two classes consisting of 60 students each. In the final exam, from every unit, one analytical question was asked and the percentage of students attempting and scoring above $60 \%$ marks was calculated. Below is the analysis:
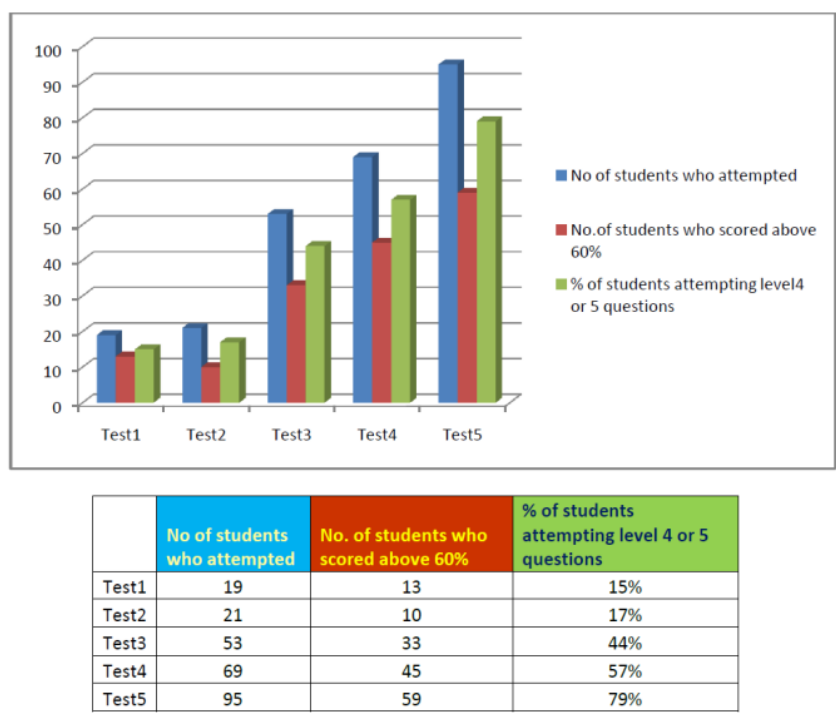

Fig 7: Statistics indicating the improvement of results The nature of the problems, the grouping of students and the follow-up lectures are the major contributing factors that improved the students' performance.

iii) MAM -Mentor Assisted Micro projects - a shift from "learning by listening to learning by doing"

Mentor Assisted Microprojects involved pairing fourth year students with first year students.

Mentors typically built relationships with first year students by meeting with them during microproject class or sometimes after college hours in order to complete the projects.

The idea of micro projects was a subtle one. The aim of micro projects was to make a connection between activities and the underlying conceptual knowledge that students had to foster. 


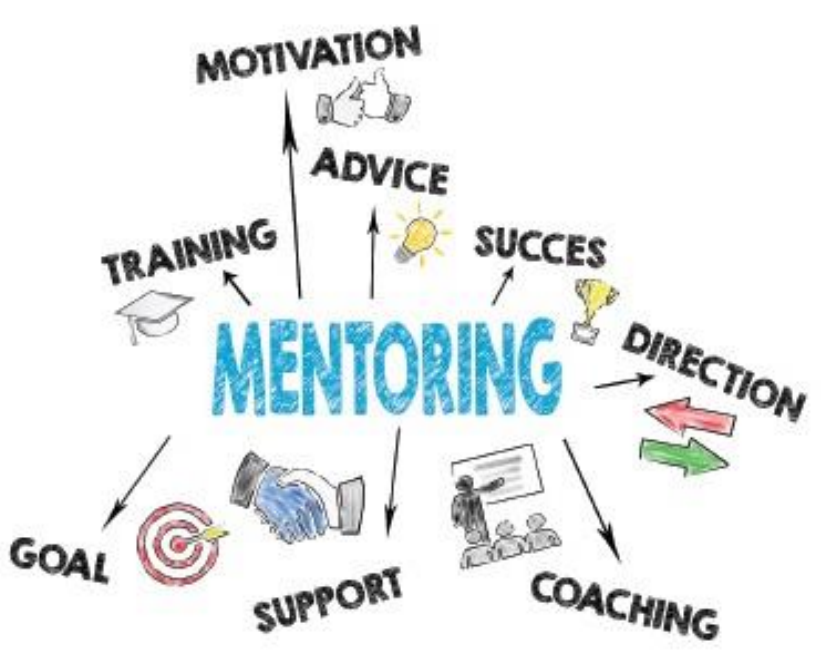

Fig 8: Courtesy - Google images.

Ted Lewis (2007) declared that mathematics and science curricula alone might not be able to produce the kind of authentic representations that characterize and necessitate ill-defined and creative work. [7].

Adapting university curriculum and instructor teaching styles may prevent the loss of struggling students who are intellectually capable of succeeding (Fazarro \& Stevens, 2004).[8]

In PBL the student role changes from "learning by listening to learning by doing" (Stauffacher et al., 2006: 255). [9]

Micro Projects are a small version of project based learning focussed on the application, and possibly the integration of previously acquired knowledge. Projects were carried out in small groups.

In previous years microprojects were guided only by the faculty. This time mentors were also included.

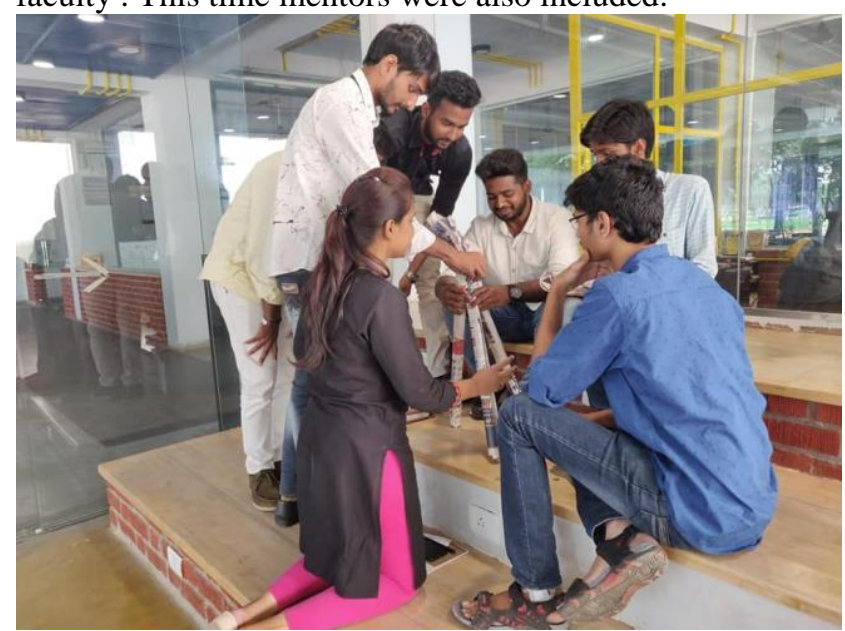

Fig 9: MAM- Mentor Assisted Microproject Team
Students work in groups of 4-5 for the micro projects. Students choose a project from a list that the faculty has prepared. Each project group is assigned a faculty advisor apart from the student mentor . Faculty member supervise three to five project groups as well as teaching coursework in their specialty area.

Micro projects incorporated a good deal of student more autonomy, choice and responsibility than in the case of traditional instruction.

The adoption of project-based learning (micro project) as a key component of curriculum encourages students to learn by investigating a complex question, problem or challenge. It helps in enhancing the higher order thinking by engaging in active learning.

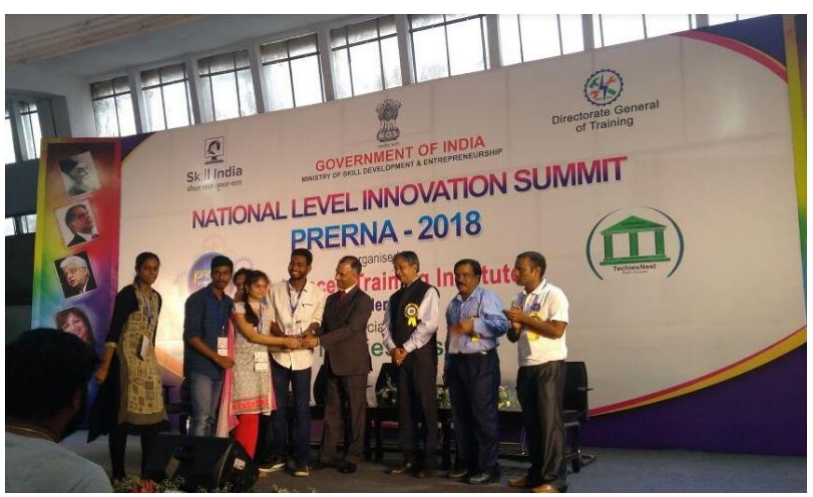

Fig 10: First yr. Students winning competitions at national level

(iii) COSHISS - Consortium Of Students Helping Improve Speaking Skills:

One of the key component of $21^{\text {st }}$ century skills is communications and the need for acquiring strong communication abilities has been shown in several studies across engineering disciplines (Milke, et al. 2013, Nicometo, et al. 2010)[10]. In fact, ABET curriculum requirements ensure that institutions teach those skills to their graduates [11].

Favourable circumstances do not exist for engineering students to practise communication skills and is one of the weaknesses that can impact significantly on an engineer's communication skills.

There are shy students in every classroom. How do you help these students step out of their discomfort zones and participate in class, was the main idea for including seminar hours every week to improve oral communication skills. But it was observed that many students find seminar presentation is traumatic and used to skip the classes.

In an effort to help students overcome the trauma, an activity named COSHISS - spelled as "koshish" (the hindi meaning of KOSHISH being TRY / EFFORT) was rolled out. 
The entire class of 60 students is divided into 3 batches, each consisting of 20 students. Again a group of 4 students was formed (from the 20 students group) and topics for presentation were declared in advance. The students had to ensure that every member of the team gives an oral presentation of the topic.

This activity was implemented for all 960 students with 14 faculty members exclusively assigned for this activity.

Students teaming up to share and ensure their team members present the topics revolve around a complex series of interactions between team members over a time and improves the skill of communication, apart from planning and team working.

The goal is to try and give them topics that make them feel that they are contributing to the seminar presentation and feel connected to other students encouraging them to interact with other students.

The assessment was done twice. Firstly each student was assessed for their individual presentation. Later 4 members were teamed and were asked to give a group presentation. The below graph along with the data indicates the improvement seen in all the 4 teams after COSHISS was implemented.

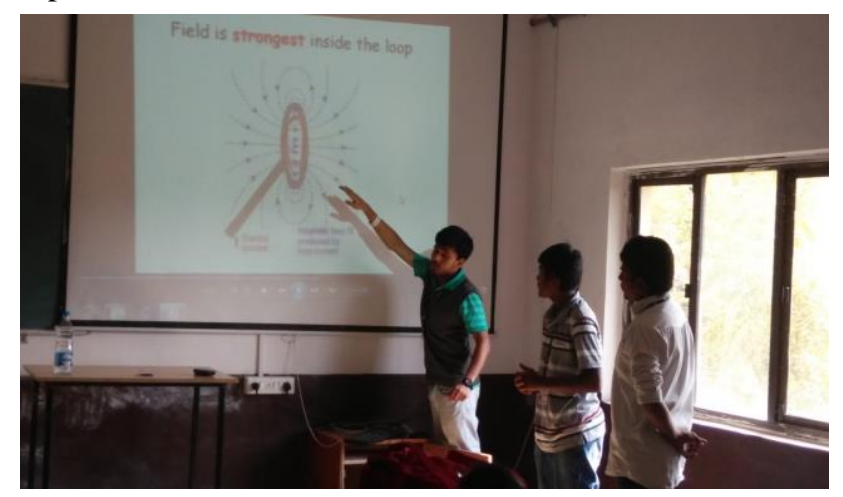

Fig 11: COSHISS activity in progress

The COSHISS has encouraged and enhanced the interpersonal skills apart from improving the communication skills.

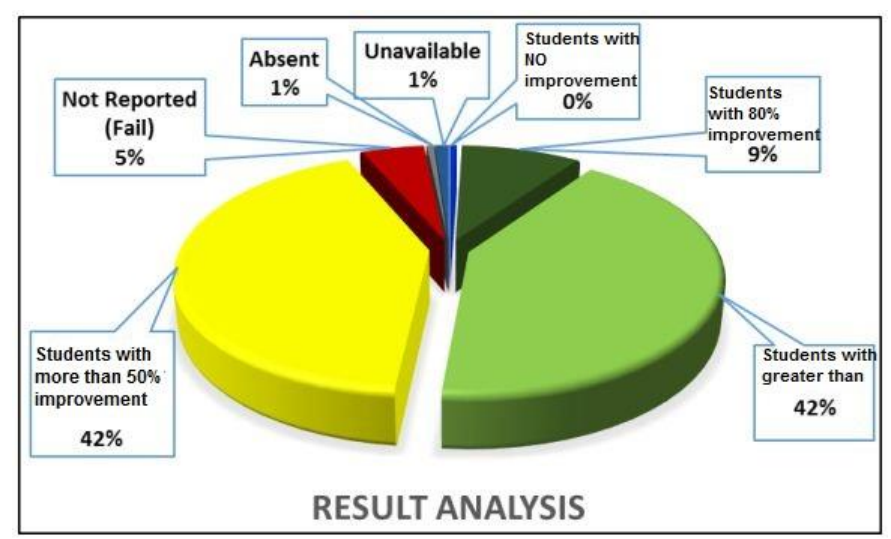

Fig 12: Statistics indicating improvement in the speaking skills

Impact of the methods on results:

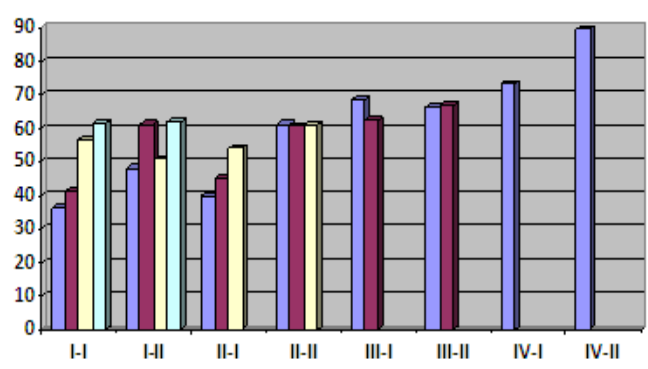

$\square$ 2015-16

-2016-17

$\square$ 2017-18

만-19

\section{Result analysis}

Fig 13 : Graphical representation of improvement in results.

It is very clear from the above statistics that the end semester results have also shown a remarkable increase in every semester starting from first year..

\section{Conclusion:}

Few students claimed to have felt under pressure during active learning classes but majority of the students claimed that these activities enabled them to analyse, search and think of different solutions.

It can be concluded that the activities encouraged the students to think out of box and stimulate thought process. In most of the cases we observed positive results. Even faculty favoured the idea of infusing active learning strategies into the teaching.

The COSHISS adapted in classes, was effective in terms of increasing communication skills and improved student participation. The adoption of new teaching methodologies facilitated the development of faculty in nurturing the skills of the students.

Project-based learning approach encourages students to learn by investigating a complex question, problem or challenge. It helps in enhancing the higher order thinking by engaging in active learning. PBL enhances the learner's capacity to apply his academic knowledge and cognitive skills to solve new challenges by demonstrating and applying both academic knowledge and cognitive skills.

The effective way to engage students in project-based approach is to allow learners to identify projects that matter and allow them to explore those projects naturally.

Blended learning tries to combine the digital world and inclass teaching. For empowering learners, a true blended learning approach with a right mix of highly relational active and inquiry-oriented programmes, both online and offline are must. 
It can be concluded that blended learning has proven to enhance the efficiency and effectiveness over single delivery mode programs. It is clear that the methodologies implemented have transformed students from learners to leaders.
Institutions. Journal of Industrial Teacher Education, 41(3),

9. Stauffacher, M., A. Walter, et al. (2006). "Learning to research environmental problems from a functional socio-cultural constructivism perspective: the transdisciplinary case study approach." International Journal of Sustainability in Higher Education 7(3): $252-275$

10. Milke, M W, C Upton, G F Koorey, and A D O'Sullivan. "Improving the writing of engineering students through portfolios.” ASEE Annual Conference and Exposition. Atlanta: ASEE, 2013. 13

11. ABET Criteria for Evaluating Engineering Programs, (2007)

\section{References:}

1 Six C's for effective teaching - Journal of Engineering Education Transformations, Special Issue, eISSN 2394-1707.

2. Bonwell, C. C., \& Eison, J. A. (1991). Active Learning: Creating Excitement in the Classroom. ASHE-ERIC Higher Education Report, Washington DC

3. Marx, J. D., and K. Cummings. 2007. Normalized change. American Journal of Physics 75:87-91.

4. Felder, R.,2006. Teaching Engineering in the 21st Cent ury witha 12th Century Teaching Model: How Bright is that? Chemical Engineering Education, 40 (2), 110113.

5. Chu, K.C. \& Lai, P., 2002. How engineering students' problem solving skills can be improved? World Transactions on Engineering Technology Education, 1 (1).

6. Wankat and Oreovicz, 1992,Wankat, P.C., \& F. S. Oreovicz, (1992). Teaching Engineering, available at: http://dequim.ist.utl.pt/wankat/. Accessed 2011/03/9.

7. Lewis, T. [Ted] (2007). Engineering education in schools. International Journal of Engineering Education, 23(5), 843-852.

8. Fazarro, D. , \& Stevens, A. (2004). Topography of Learning Style Preferences of Undergraduate Students in Industrial Technology and Engineering Programs at Historically Black and Predominantly White 